\title{
Promoting a Collective Voice from Parents, Educators and Allied Health Professionals on the Educational Needs of Students on the Autism spectrum
}

Globally, the prevalence of autism spectrum disorder has increased substantially. In 2014, an estimated 1 in 59 children aged 8 years in the United States of America were diagnosed on the autism spectrum (Baio et al. 2018). Furthermore, the number of students on the autism spectrum attending mainstream schools has grown (Ravet 2011; Soto-Chodiman, Pooley, Cohen and Taylor 2012) as a more inclusive approach to education for all students has evolved (Farrell and Ainscow 2002; United Nations Educational Scientific and Cultural Organisation 1994). However, despite rapid expansion in autism research, effective support for the educational needs of students on the spectrum remains a challenge for students, teachers, parents/carers and specialists working in schools (Humphrey and Symes 2013; Lindsay, Ricketts, Peacey, Dockrell, and Charman 2016; Siegel 2018; ). Inclusive education can contribute to improved quality of life, and educational and social outcomes for all students including those on the spectrum (Humphrey and Symes 2013; Kurth and Mastergeorge 2010; Sansosti and Sansosti 2012; Siegel, 2018). However, research investigating the impact of inclusive education for students on the spectrum has produced mixed findings (Humphrey and Symes 2011; Osborne and Reed 2011; Waddington and Reed 2017). Debate is ongoing regarding how well inclusive education policies are being translated into inclusive practices (Humphrey 2008; Roberts and Simpson 2016).

Inclusion for students on the spectrum is a "complex process" (Ferraioli and Harris 2011, p.25) with studies researching outcomes of inclusion limited in "number, scope and sample size" (Ferraioli and Harris 2011, p.25). Academic and social outcomes are evident but there are no uniform positive outcomes (Sansosti and Sansosti 2012). Although most students make some gains, they are not competing on an equal footing with peers in inclusive 
settings, with many requiring additional specialised support (Ferraioli and Harris 2011; Sansosti and Sansosti 2012). Students on the spectrum continue to experience poor educational and post-school outcomes, and underperformance relative to their cognitive ability (Ashburner, Ziviani and Rodger 2010; [Colleague], [Author 6] and [Colleague] 2015; Estes, Rivera, Bryan, Cali and Dawson 2011; Jones et al. 2009). Educational outcomes of students attending mainstream schools are no better than those enrolled in specialist classrooms (Waddington and Reed 2017) with students highlighting difficulties they experience in mainstream contexts (Ashburner et al. 2010; Hebron and Humphrey 2014; ). Students on the spectrum report regularly experiencing stress in mainstream educational contexts (Okajima, Kato, Yoshitomi, Kanaya and Sakuta 2017;) and increasing incidences of behavioural and emotional difficulties (Ashburner et al. 2010; Osborne and Reed 2011). Education and inclusion of students on the spectrum encompasses two dominant and contradictory perspectives: rights-based and needs-based (Ravet 2011). A rights-based perspective promotes ending educational segregation and appeals for academic and social inclusion of all students in mainstream schools (Centre for Studies in Inclusive Education 2008). A needs-based perspective prioritises preservation of a range of educational provisions to meet the unique and distinctive needs many learners exhibit (Lindsay 2007; Low 2007, 2013). A needs-based approach highlights lack of evidence to support outcomes of inclusion and exclusionary dangers that can result. These contradictory and opposing theoretical views on inclusion also create confusion in stakeholders understanding and interpreting inclusive practices (Ravet 2011), and inconsistency in how inclusion is translated into practice to support students with additional needs. Recently however, an integrated approach to inclusion drawing upon rights- and needs-based perspectives has been proposed. This approach implements distinct pedagogies based on individual student needs to maximise the success of inclusive practices for all students including those on the spectrum (Ravet 2011). 
More recently the neurodiversity movement extended these notions with an emphasis on strength-based approaches and goals responsive to and in collaboration with the autism community. This movement focuses on improving quality of life by minimising barriers to inclusion through shifting of attitudes, changing social and physical environments, and working beside and with the consent of the autism community (den Houting 2019). It is therefore timely to re-examine the educational needs of students on the spectrum from different stakeholder viewpoints within the autism community to support an integrated approach to inclusion in schools informed by the neurodiversity of student needs (den Houting 2019; Ravet 2011).

One method for examining different stakeholder perspectives is to conduct a needs assessment or needs analysis (Soriano 2013). According to Powers and Knapp (2010, p. 120) a "needs analysis uses a problem-solving process for the purpose of collecting, organising, and presenting information that describes the needs of a target population and evaluates their importance relative to demand". Different stakeholder views are gathered to promote a "collective voice" and identify future research priorities and research knowledge translation activities suited to stakeholders' needs. The needs analysis process allows important messages from different target audiences to be acknowledged and identified (Grimshaw, Eccles, Lavis, Hill and Squires 2012; Soriano 2013).

The importance of translating research knowledge into practice is well established (Grimshaw et al. 2012). While hoping an increase in autism research will result in benefits for the autism community and different stakeholders within it (Pellicano, Dinsmore and Charman 2014), there has been increasing attention on evidence that highlights the gap between research and practice (Grimshaw et al. 2012). A needs analysis facilitates development of knowledge translation products responsive and tailored to different stakeholder needs; while collecting a range of views from stakeholders in the autism 
community offers well-informed research that is responsive to the needs of the autistic community (Pellicano et al. 2014) and enables effective translation into practice and policy.

The current study adds to a growing body of research that has demonstrated mixed results when investigating inclusion of students on the spectrum from different stakeholder perspectives (All Party Parliamentary Group on Autism 2017; Pellicano, Bölte and Stahmer 2018; Pellicano, Dinsmore and Charman 2014; Roberts and Simpson 2016; Stokes et al., 2017). A recent literature review by Roberts and Simpson (2016) suggested some common themes included the level of knowledge and understanding of staff, support required for autism-specific characteristics particularly social understanding and interactions, and social communication. Barriers related to a lack of collaborative approaches and the need for more training, resources and funding. While the authors acknowledge the importance and priority that should be given to acknowledging children's views (Gillett-Swan \& Coppock, 2016) in formulating policies and support for their own educational needs, the focus of the current paper was to gather information from the collective view of parents, educators and allied health professionals.

\section{Research Aim}

A large nationwide Australian needs analysis study - [details hidden for blind review] ([Author 1] et al. 2016) explored the educational needs of students on the spectrum (aged 5-18) from the perspectives of different stakeholders including parents of school-aged students on the spectrum, and specialists and educators working with school-aged students on the spectrum. The findings can be used to identify enablers and barriers to student achievement, and to inform implementation of effective and socially-valid inclusive practices that meet the educational needs of students on the spectrum (Baldry-Currens and Blithell 2000). Data analysed in this paper addresses the following research questions: 
(1) What do key stakeholders perceive are the educational needs of students on the spectrum (aged 5-18 years)?

(2) What do stakeholders identify may influence provision of support and services to meet the educational needs of students on the spectrum (aged 5-18 years)?

(3) Are there identified differences in stakeholders' views according to the characteristics of the student with autism, respondent or education settings?

\section{Method}

The needs analysis was undertaken using a mixed-methods sequential explanatory design (Cresswell 2012; Cameron 2009; Ivankova, Cresswell, and Stick 2006). The initial nationwide survey incorporated both quantitative Likert scale and open-ended qualitative questions. Likert scale questionnaires are an efficient method to reach large groups of participants and determine the extent to which stakeholder groups agree or disagree with a particular construct (Gavin 2008). After surveys closed, further qualitative data was gathered through semi-structured interviews to extend and identify factors related to survey findings (Driscoll, Appiah-Yeboah, Salib, and Rupert 2007).

\section{Participants}

Participants were recruited from all Australian states (i.e., Queensland, New South Wales, Victoria, South Australia, Tasmania and Western Australia) and territories (i.e., Australian Capital Territory and Northern Territory), including rural and remote areas, and encompassing all educational sectors and organisations working with school-aged students. A purposive sampling (Patton 2002) approach used to recruit participants nationally involved first identifying relevant organisations, people and support groups representative of the three stakeholder groups (including parents of school-aged students on the spectrum aged 5-18 years of age, educators of students on the spectrum, and specialist educators and allied health 
professionals working in schools). Information about the study was disseminated through these organisations facilitated recruitment of participants. Groups that were approached included: parent-based organisations and support groups; autism-specific organisations; educational organisations; professional organisations and networks; researcher networks; and social networking groups (Twitter and Facebook).

In total, 99 national and state-based organisations were sent an information flyer, which included a link to the survey; 33 of these (12 national and 21 state) agreed to disseminate the flyer to their respective members. Of the 66 organisations who did not disseminate the flyer, 58 did not respond to the initial contacts, 2 declined to disseminate the information, and 6 emails were returned as "undeliverable". Other recruitment methods included word of mouth, radio interviews, conferences, email signatures of researchers, flyers, and advertisements placed on relevant organisational and professional websites.

To achieve the broadest selection of participants possible the research team monitored response rates and, where response rates were lower, used a targeted strategy sending recruitment information electronically to social media networks and organisations specific to the targeted stakeholder groups or geographic locations. Once recruitment began, geographical locations or stakeholders groups that were showing lower or inequitable response rates were identified and a more targeted recruitment strategy in these areas or within these participant groups was developed using the range of recruitment methods described above to maximise the broadest uptake of the research possible.

Participants who completed the online survey could indicate interest in a follow-up qualitative interview and provide their contact details at the end of the survey. Willing participants were sorted by state then randomly selected individuals from each group were contacted and invited to participate in an interview. Consequently, 10 parents of students on 
the spectrum, 10 educators and 10 specialists working with students on the spectrum were recruited for interview.

\section{Instrumentation}

The online survey specifically developed for this study included quantitative and qualitative questions customised for each key participant group (parents, educators, and specialists) to ensure the survey accurately reflected the participants' differing roles and perceptions of the educational needs of students on the spectrum. The different versions included:

- Parents survey - designed to cater for parents of school-aged students on the spectrum (aged 5-18 years).

- Educators survey - designed for educators in a range of roles (e.g., administration, class teachers, ancillary staff) who were involved in or had previously been involved in the education of school-aged students on the spectrum.

- Specialists survey - completed by a range of specialist support staff (e.g., education specialists, allied health professionals, psychologists) who were working or had previously worked to support school-aged students on the spectrum.

Survey questions were based on the core characteristics of the autism spectrum (American Psychiatric Association (APA) 2013) and findings from the Australian Advisory Board on Autism Spectrum Disorders (AABASD) position paper (2012) which elucidated eight educational principles for providing school-aged Australian students on the spectrum with the most appropriate education (see Table 1).

\section{[INSERT TABLE 1 HERE]}

The experience and knowledge base of a multidisciplinary research team informed development of survey questions and was used as an instrument blueprint to "guide the 
creation of the survey items as well as the collection of validity evidence" (Menold, Jablokow, Purzer, Ferguson and Ohland 2015, para 1). The process to create the survey items was based on elements of Messick's unified theory of validity (1995) and used multiple resources including: (a) research from the field, (b) a review of existing survey instruments and c) utilising the expertise of the research team who were all experienced researchers in the field (Menold et al. 2015).

Each survey instrument was initially piloted with parents, educators and specialists who volunteered in consultation with an autism community organisation involved in the study. In total, 32 people were involved in piloting the surveys (12 educators, 10 parents and 10 specialists). During the piloting process participants completed a feedback sheet and commented about the survey as a whole and on individual questions. Feedback primarily focussed on the length of time to complete the survey and the perception of repetition across some questions. In response to feedback, surveys were shortened and repetitious questions removed.

Each survey contained demographic questions relevant to the targeted stakeholder group. For example, educators and specialist personnel were questioned about their prior experiences working with school-aged students on the spectrum and their professional learning experience and needs. The parents survey captured information about the parent's experiences and perceptions regarding the professional learning needs of educators working with their child.

The main body of the survey included Likert questions to gather participant perceptions of key topics related to the core characteristics and needs of students on the spectrum (APA 2013) including: (a) school needs; (b) sensory needs; (c) behavioural and mental health needs; (d) transition needs; (e) school connectedness; (f) use of technology; and (g) support experiences including remote consultative approaches. Open-ended questions 
allowed participants to provide further information, examples or comments regarding their answers on Likert questions.

Interview questions explored stakeholder perceptions of needs for which students on the spectrum required most support in school settings, most commonly implemented supports, and factors that facilitated or inhibited providing support. To ensure consistent understanding of the questions and similar interpretation of the terms by each stakeholder group, examples were provided for some concepts e.g., social-emotional needs. Reflecting the individualised nature of each survey and the differing role each stakeholder group played in supporting students on the spectrum in schools, each stakeholder survey varied in length (75 specialists questions, 67 educators questions and 55 parents questions). Table 2 displays survey questions (including response format) and interview questions of this study.

[INSERT TABLE 2 HERE]

\section{Procedure}

Participants received information to self-select which survey they completed and an online link directing them to an information page about the research project, expectations of participation, and potential benefits of the research. Participants were then given the option to proceed (consent) or discontinue (opt out). The survey was hosted by SurveyMonkey and took approximately one hour to complete. To maximise opportunity for participation, the survey link was open from late August 2014 to late January 2015. Participants recruited for interviews could choose to complete the interview by phone, online or face-to-face depending on their location. Interviews lasted approximately 20-30 minutes and were recorded then transcribed verbatim for analysis. Informed consent was obtained from all individual participants included in the study. 
Primary ethics approval to conduct the low risk study was initially obtained from [University 1 - details hidden for blind review] Research Ethics Approval Committee. Secondary ethics approval was then obtained from other organisations involved including Autism Spectrum Australia (Aspect), Queensland Government Department of Education and Training, and [University 2]. Gatekeeper approval was obtained from Autism Queensland, Asperger Services Australia, and Brisbane Catholic Education.

\section{Data Analysis}

Survey responses were exported from SurveyMonkey to SPSS Version 23 and screened for invalid (e.g., duplicate submissions) or incomplete surveys (i.e., discontinued mid-survey which were excluded from analysis). Data reduction techniques included multiple correspondence analysis (MCA) and principal components analysis (PCA) to reduce survey questions to a manageable number of dimensions for analysis. Two-step cluster analysis was also used to identify sub-groups of participants based on characteristics. Analyses are reported in brief below, with further details provided in the online supplementary section.

Additional education supports provided for students on the spectrum (parents and educators, Q20): MCA reduced the number of supports to three categories: educational supports (e.g., advisory teacher); allied health professionals support (e.g., occupational therapist); and in-school supports (e.g., 1--1 support). Total scores were calculated by summing the number of supports reported for each category. The solution accounted for $48 \%$ of the variance in responses, with an average Cronbach's alpha of .691 for the dimensions.

Types of support students receive (parents, Q21): PCA grouped the types of support students received into two categories: educational supports ( 3 items e.g., teacher aide), $\alpha=$ .637 , and allied health professionals support ( 2 items e.g., occupational therapist), $\alpha=.754$. 
Types of support professionals provide (educators and specialists, Q33): PCA grouped supports provided into three categories: internal support ( 2 items e.g., consultation with teachers), $\alpha=.871$, external support ( 3 items e.g., consultation with parents), $\alpha=.716$, and student support ( 2 items e.g., consultation with the student on the spectrum), $\alpha=.738$.

School alignment with AABASD principles (parents, Q48): All principles loaded onto a single factor with a Cronbach's alpha of .902. Scores for the 6 items were averaged to create a total score for school compliance with AABASD principles.

Characteristics of students on the spectrum having the greatest impact on learning and requiring the most support (parents, educators and specialists - Q49): PCA indicated a single needs factor. However, academic/learning needs was conceptually different from the non-academic needs (socioemotional, communication, sensory and behaviour) which was supported by the increase of Cronbach's alpha from .826 to .857 with "academic/learning needs" removed and analysed separately.

Barriers to supporting the challenging behaviours and more complex needs of students on the spectrum (parents, educators and specialists - Q56): PCA distinguished between barriers related to school climate (e.g., lack of support from managers to implement changes), $\alpha=.932$, and resources (e.g., lack of time, inadequate funding to support the student's needs), $\alpha=.723$.

Quantitative analysis was undertaken in two parts. Initially, Kruskal-Wallis tests with pairwise comparisons examined differences in identified needs and barriers to support identified by parents, educators and specialists. A series of Friedman two-way analysis of variance by ranks with paired comparisons examined possible differences in views regarding educational needs, priorities and barriers within participant groups. Bonferroni corrections were applied to all pairwise comparisons. Significant findings are reported together with effect sizes in the online supplementary section. 
Subsequent Kruskal-Wallis and Friedman's tests with pairwise comparisons compared clusters within participant groups on various outcomes. For parents, these included school alignment with AABASD principles, educational support needs and barriers, and availability and use of supports within educational settings. For educators and specialists, these included educational support needs and barriers, and availability and provision of services to support students on the spectrum.

Responses to open-ended survey questions and interview questions were subjected to qualitative content analysis and "quantitised" which involved identifying the frequency of topics discussed by parents, teachers, and specialists (Onwuegbuzie and Teddlie 2003). Topics were classified according to categories of student needs. Selected notes were also made relevant to the text to provide examples of typical and unique responses for each participant group. Importantly, in some instances parents had more unique responses focused on the specific needs of their own child whereas specialists and educators focused more on their experiences with a range of students on the spectrum and in some situations shared more typical responses of note. Two researchers conducted an independent analysis of these notes and conferred with the first lead author to verify their interpretation of codes. Qualitative data also triangulated the quantitative findings, in that respondents were given the opportunity to further discuss the data they had provided on the Likert survey questions.

\section{Results}

\section{Survey Respondents and Interview Participants}

After excluding invalid surveys, data from a total of 1,361 participants were available for analysis, comprising 934 respondents for the parents survey, 248 for the educators survey, and 179 for the specialists survey. Table 3 presents a summary of participant characteristics for survey data. Further details about the sample characteristics including a breakdown of 
differences between participant groups and respondents and non-respondents is available in the online supplementary section. Table 4 presents a summary of participant demographics for interview data.

\section{[INSERT TABLES 3 AND 4 HERE]}

\section{Quantitative Survey Data}

\section{Perception of Educational Needs}

Responses to survey questions are summarised in Figure 1 and Table S3a in the online supplementary section. Responses indicate academic and non-academic needs, and barriers to support were rated highly (medians of 4-4.75) at a group level, although the range of responses varied considerably (i.e., 1-5) across groups. All stakeholder groups viewed nonacademic needs as requiring greater support than students' academic needs, with effect sizes moderate for professionals (Kendall's $W_{\text {range }}=.23-.43$ ). Parents rated academic/learning support needs more highly than specialists, while educators rated non-academic needs more highly than parents, although the effect sizes were very small $\left(\eta^{2}=.005-.009\right)$.

\section{Barriers to Support}

Parents viewed school climate (e.g., management and workplace support) and resourcing (e.g. lack of time) as a greater barrier to support than educators did, although the effect size was small $\left(\eta^{2}=.007-.032\right)$. Specialists considered school climate as a greater barrier to supporting students on the spectrum compared to educators. All stakeholders gave similar rankings to school climate and resource related barriers, which suggested that barriers to support were high. 


\section{Type of Support, Delivery and Context}

\section{Parents views}

Parents results with largest effects included parents: (a) who had students attending specialised settings or accessing more specialised support within mainstream settings; (b) who reported their child having access to and utilised educational supports to a greater extent; and (c) of students who had more access to allied health professionals support than parents of students attending mainstream settings without specialised input. Unsurprisingly, parents of students in distance or home education indicated their child had the least access to and utilisation of educational supports. Similarly, parents of students in remote schools reported greater barriers to supporting students on the spectrum due to school resources compared to parents of students in urban or rural schools (see Table S4e, online supplementary section).

Spearman's correlation indicated availability of and access to supports was positively associated with perceptions of alignment with AABASD principles. This included availability of educational $(r=.428, p<.001)$ and allied health professionals support $(r=.247$, $p<.001)$ and accessing educational $(r=.266, p<.001)$ and allied health professionals $(r=.179$, $p<.001)$ support. Accessing educational $(r=.092, p=.011)$ and allied health professionals $(r$ $=.084, p=.021)$ support was also associated with higher ratings for academic needs. While availability of educational supports $(r=.096, p=.008)$, and accessing educational supports $(r$ $=.084, p=.021)$ were associated with higher ratings for non-academic needs. Lower ratings for barriers due to school climate were noted by parents who reported availability of allied health professionals $(r=-.099, p=.009)$ support, and access to allied health professionals services $(r=-.092, p=.016)$. 


\section{Educators and Specialists Views}

Educators felt there were more education and allied health professionals supports available at their schools compared with parents. While specialists indicated spending more of their time providing external (consulting with parents and outside agencies, report writing) and internal (consulting with administrators and teachers) support compared to educators (See Table S3b, online supplementary section).

Educators and specialists results with the largest effect size included educators working in specialised educational settings who reported that students had greater access to allied health professionals supports than educators working in mainstream settings (See Table S5a, online supplementary section). Specialists working in schools with 101-500 students spent more time consulting with administrators and class teachers than specialists working in schools with 1-100 students, or settings where the number of students was not stated (See Table S6c, online supplementary section).

Non-parametric correlations for educators indicated availability of educational supports $(r=-.246, p=.001)$ and providing support to administrators and teachers $(r=-.198$, $p=.01)$ were associated with fewer school climate-related barriers to supporting students on the spectrum. Similarly, availability of allied health professionals supports $(r=-.155, p=.01)$ was associated with fewer resource related barriers, although external consultation was associated with more resource-related barriers $(r=.172, p=.025)$. There were no significant inter-correlations between needs or barriers and supports provided by specialists.

\section{Qualitative survey and interview data}

Figure 2 provides a summary of themes and sub-themes generated from the analysis of qualitative data gathered in open-ended survey questions and interviews. Three key themes regarding students' needs were identified by all three participant groups: 
(1) School staff understanding the autism spectrum.

(2) Recognition and support for the unique and diverse educational needs of students on the spectrum.

(3) Building school capacity.

However, across different participant groups, parents discussed these themes in relation to the specific needs of their own child, while educators and specialists focused on their experiences with a range of students on the spectrum. Educators and specialists highlighted the heterogeneous and idiosyncratic nature of student needs with one specialist emphasising how needs varied "from student to student". Unsurprisingly, in comparison, parents focused on their child's more specific and unique needs as part of this heterogeneity. As one parents commented, "This is hard for me to answer on behalf of "students with ASD"”.

\section{[INSERT FIGURE 2 HERE TOP]}

Theme 1 - Understanding of the autism spectrum. Data from interviews and open-ended survey questions emphasised and acknowledged the importance of all staff in schools (not just the class teacher) being able to recognise, understand and be aware of the individual needs of students on the spectrum to successfully support their learning. All interviewed participants strongly agreed that educators required more knowledge and understanding to effectively implement support to meet the educational needs of this group of students. For example, educator Mary ${ }^{1}$ emphasised a lack of understanding of students on the spectrum in schools and a lack of training to combat this issue when she stated there are "not a lot of teachers in general schools that understand the needs of ASD students... and more training is

\footnotetext{
${ }^{1}$ Pseudonyms have been used throughout the paper.
} 
needed". Similarly, a parent response on an open-ended survey question stated it is about "being flexible and understanding that [my son] had a different head space to the other students and a willingness to try and understand that he was not coming from the same direction was key". Clinical psychologist, Linda, described the importance of "better understanding of individual learning needs to facilitate access to curriculum and achieve". Sarah, a specialist supporting schools, stated, "Just understanding that students with ASD work in a different way. Then that understanding promotes adjustments to the way people teach or how people teach or perhaps the environment around them depending on the individual". Amy, a school principal of an autism specific school, summed up these ideas when she stated:

It's knowledge and skills and it's about the science of autism and the science of teaching; not just good work, good intentions, novelty, but really looking at evidence-based practice and what works for our young people so that they can (a) engage in learning, they can be supported to develop learning-ready behaviours and appropriate social behaviours. Then (b) get on with the job of learning, so that we can, at whatever ability level, support young people to develop skills they'll need to be successful in later life.

Notably, all three participant groups commented more frequently in open-ended survey questions that understanding and awareness of the social-emotional, sensory, and behavioural needs of students on the spectrum were more important compared to understanding students' academic and communication needs.

In a related area, respondents indicated that acknowledging how social-emotional, communication, academic, sensory, and behavioural needs are interrelated and influence each other was also important. For example, participants emphasised meeting the social-emotional, behavioural, sensory, and communication needs of the student on the spectrum would create an environment that would optimise learning and promote opportunities for positive academic outcomes. Data emphasised the importance of recognising the diversity of needs 
and developmental aspects of needs of students on the spectrum. For example, Kelly, a specialists working with schools, stated, "Teachers having more of an understanding of what ASD is and how it can present itself in a number of different ways", while Mary highlighted regarding teachers:

There is not a lot of understanding of what the children require and the diversity. Don't understand that they are not all the same and what worked today won't necessarily work tomorrow. We don't cater well in schools or prepare other students around them for different learning styles/needs.

Theme 2 -Educational needs of students on the autism spectrum. Theme 2 supplemented quantitative findings by highlighting the importance of going beyond a traditional focus on academic learning to adequately understand the needs of students on the spectrum. This requires recognition that some of the more individualised, unique and autism-specific needs of students on the spectrum (e.g., in the social-emotional learning, self-regulation, executive functioning, sensory, behavioural, and communication domains) are integral to the educational needs of this group of students, and adequate support therefore involves considering all of these domains of development. Most notably, qualitative survey data provided by all participant groups reflected the higher levels of support required for socialemotional needs of students on the spectrum. For example, one specialist highlighted that when supporting students on the spectrum in schools, "It is the social-emotional understanding of the hidden curriculum". This was endorsed by educators comments about the "need to concentrate on social foundation skills" while parents described it as "the need for help to interpret the school world". Furthermore, survey participants across all stakeholder groups stressed the impact of anxiety on student learning, highlighting that managing anxiety was a top priority for social-emotional support for this group of students. Following support for anxiety, participants indicated support was needed for behavioural, sensory, and 
communicative needs, and specified that a comparatively lower level of support was needed for academic learning.

Participant interviews provided further evidence for recognising the social-emotional needs of students on the spectrum as a priority for support in schools to ensure the best outcomes for learning in the school environment. For instance, classroom teacher Jo stated, "I've found with ASD students is they need a lot of help with social skills within the classroom. Because that tends to impact on everything else". While teacher Danielle stated, “Social programs - taught specific skills - recognise if things aren't going right and what would be the best choice to make everyone happy. How to start or enter a conversation or game, how to make friends". Specialists who were interviewed also highlighted socialemotional understanding as a significant need, providing comments such as "Social aspect and understanding social rules in the school, classroom and playground", (Kelly) and "Social support in playground to make positive connections" (Linda). Parent Nina also highlighted this when she discussed the growing need for social-emotional support for her son:

\footnotetext{
He's actually quite gifted in academics but he has a lot of social issues, particularly as he gets into the higher grades and as social interaction becomes a lot more intricate and probably a higher level of social-emotional (support). He doesn't tend to keep up in those areas with his peers. So his level of frustration and not understanding what's going on in certain interactions means that he often can have certain outbursts. He really needs a much higher level of support socially and emotionally as opposed to probably learning.
}

Parent Amanda described the trauma that can emerge if social-emotional aspects of learning are not supported, stating, "Recess and lunch are unsupervised so there is social trauma that happens to child".

Interview data also reflected the need for further attention on the impact of anxiety on students on the spectrum. Betty, a specialist teacher working in the field illustrated how anxiety impacted on learning, saying, "Anxiety, once we address what [may] be an anxious 
situation for the person, they're then able to concentrate more on the content and being productive in their course", while parent Kirra described the impact of her son's anxiety on his ability to participate in school: "My son, in particular, suffers a lot from anxiety in not knowing what's going on, and he comes out in quite defiant behaviour. That makes it very difficult at school". Similarly, class teacher Danielle recognised the importance of helping students to self-regulate their anxiety in the classroom by "giving leeway to have a break in the corner".

Additionally, participants discussed some key elements they felt were needed to ensure all educational needs of students on the spectrum within these domains are met. These are summarised in Table 5. Overall, these results stress the importance of educators providing a range of strategies to support all students' needs, not just their academic needs. As illustrated in Table 5, participants suggested ideas for providing adjustments to the school environment to support students' social-emotional, communication, sensory, behavioural, and academic engagement and organisation.

\section{[INSERT TABLE 5 HERE]}

Theme 3 - Building school capacity to meet the needs of students on the autism spectrum. Participants highlighted the importance of building school capacity to meet the educational needs of students on the spectrum. Building school capacity was recognised by all participants as necessary to maximise success and confidence and develop a unified approach to support. Ways in which schools could build their capacity were grouped into the subthemes of:

- knowledge translation and awareness including more professional development and training for all staff to build awareness and support from others with expert knowledge; 
- funding related to the need for appropriate levels of funding to properly resource support at a material, physical and human level;

- environmental adjustments including sensory and motor breaks, and reduction of external stimuli; and

- collaboration with a range of stakeholders and the importance of all key stakeholders to help understand and appropriately support the needs of the students, translate knowledge into practice, and have the time and resources to do this effectively.

One educator described building capacity through awareness and knowledge translation as "being on the same page... So we can see basically a groundswell happening". Another specialists suggested this happened by "building an understanding of the individual student and the characteristics of that individual student including strengths and interests". From the parents' viewpoint, building awareness and knowledge meant developing understanding of their child within the school: "I guess a school that understands the difficulties, incorporates the difficulties. Support for them, not just educationally, socially as well". Another parent commented it was important to have:

\footnotetext{
A good understanding of Adam and a willingness to work on the strengths. That's what matters most to me. Everything else, the tech stuff I can provide, things like that we can do but the chalk and cheese differences are around those three things. How we communicate with his teachers, how his teachers understand Adam's strengths and weaknesses and how the teachers work to his strengths.
}

All participants considered collaboration across stakeholders as a critical aspect of enabling schools to successfully meet the educational needs of students on the spectrum. Trust and three-way relationships and communication (e.g., between students, parents, education stakeholders) were identified as important in facilitating a collaborative approach. Similarly, the implementation of a whole of school approach to including students on the spectrum, 
support from the leadership team, patience, tolerance and acceptance of the whole school community were identified as important elements of the collaborative process. Additionally, parents suggested that "building rapport", "having trust in the people in charge", and "how we communicate with teachers" were essential, while educators highlighted the importance of communication, commenting:

Lots of communication between parents and staff. Parents know their children best and things can change quickly, ASD kids cover up a lot of emotions at school and let it out at home. Having an honest relationship because not everything the school does helps/works.

For educators, building relationships with students was an important part of building the school's capacity to meet the needs of students on the spectrum stating, "Establishing a relationship with child, getting to know them and their quirks, interests and learning habits. How to get the most out of them/motivate them".

Similarly, specialists emphasised and described the role of communication and relationships stating, "Forming a trusting relationship is key. Understanding the student and then being able to respond to their unique needs". Partnerships that supported positive relationships were also emphasised: "I'd say a good relationship between the parents and the teachers and the kids. There's nothing worse than a complete breakdown in the relationship between the parent and the teacher. I feel like the relationships between all the support people are very important". Another specialist described these as "Good relationships with family good collaboration and communication to work on same journey to achieve maximum outcomes for child". Other important issues around the influence of training (e.g., building knowledge and understanding of needs of students on the spectrum), appropriate supports and adjustments and translating these into practice, resources (e.g., material human programming, time), funding and the environment (e.g., adjustments to school and classroom structure) are 
summarised in Table 6. Unsurprisingly, in highlighting what was required to meet the educational needs of students on the spectrum, participants emphasised a lack of adequate resourcing, time, and funding as barriers to effectively implementing what was required.

[INSERT TABLE 6 HERE]

\section{Discussion}

With a substantial global increase in the number of students on the spectrum attending mainstream schools (Soto-Chodiman et al. 2012) it is critical that educational needs of this group of students are appropriately recognised and addressed. To successfully achieve this enablers and barriers to meeting these needs should be considered from a range of stakeholders' perspectives to ensure relevant support is identified and implemented. To date, researchers have collected a smattering of stakeholders' perspectives but failed to consider the range of perspectives they hold or how these may coincide or differ. This study aimed to overcome this gap by nurturing a "collective" approach to stakeholders' views on a larger scale to ensure that research outcomes are meaningful to all stakeholders and enables translate of this knowledge into sustainable practice. Additionally, using research to gather a "collective" stakeholder voice enables the the rights and needs of students on the spectrum to be acknowledged and respected and supported in a collaborative, neurodiverse manner that promotes successful learning outcomes (den Houting 2019; Ravet 2011).

Current findings further illustrate previous findings supporting the importance of gathering the "collective" voice of different stakeholders (Pellicano, Dinsmore, \& Charman, 2014; Roberts and Simpson, 2016) and reveal the importance of considering the different perspectives the autism community (including parents, educators and specialists involved) bring to identifying the needs and priorities for support of students on the spectrum. While 
educators and specialists looked at needs in terms of overall classroom environment, parents reflected more on specific needs of their child.

Previous researchers have stressed that developing a collaborative education approach does not require everyone to agree, but there is a need to acknowledge that different stakeholder groups offer different perspectives that are valid and help contribute to the understanding of the student, including both their strengths and needs (Edwards and Da Fonte 2012). For example, in this study, parents identified learning needs and limited resourcing as more important than did educators. This may reflect the unique knowledge that parents have about their own child and the child's educational setting, It is important that as part of collaborative partnerships in schools educators and specialists take on board this knowledge when addressing students' needs in the classroom. Interestingly, although there were some variations in response, the data indicate parents, educators, and specialists agreed on priority areas of need for children on the spectrum. In particular, all three groups cited academic learning as requiring the lower levels of support compared to non-academic needs..

The current findings emphasise that despite the huge increase in research conducted in the field of autism over the last few decades, stakeholders agree that there continues to be significant issues and substantial barriers to adequately and appropriately meeting the needs of this groups of students successfully in school systems. Additionally, despite a wealth of research knowledge about strategies and support for this group of children, these findings emphasise and are a key reminder for the need for explicit support for educational priorities of children on the spectrum that go beyond the traditional academic learning focus often evident in schools. Of significance was the strong agreement across all stakeholder groups that effective educational support for students on the spectrum entails addressing the unique characteristics associated with the autism spectrum (i.e., social-emotional, sensory, communication needs) and perceiving these needs as integral to academic learning. The 
findings reinforce the importance of addressing the idiosyncratic presentations of these characteristics and how they are reflected in each child's unique needs. Additionally, the findings highlight that the unique, diverse and heterogeneous needs of students on the spectrum need to be acknowledged and respected and actively supported to ensure positive school experiences and successful academic outcomes for this group of children. Bespoke and flexible approaches to support learning, and the unique characteristics of students on the spectrum were also stressed, as were the importance of the necessary human and material resources to address the individual varied and changing needs of this child population in schools.

It is important to note that while the social emotional needs of children on the spectrum are a well-recognised challenge it continues to remain a priority for stakeholders. Stakeholders collectively emphasised the vital influence social-emotional needs have on the learning, academic outcomes, and educational experiences of this student group. Findings emphasise how critical it is to identify and be able address the idiosyncratic presentations of these social emotional needs. Additionally, it highlights the need for all school staff to be given the knowledge and expertise to support each student in their learning, including their social-emotional needs and support with the hidden curriculum. The hidden curriculum relates to the unwritten rules within a situation that people are often aware of without being taught them. Students on the spectrum often need help to explicitly learn and understand the unwritten rule of social engagement.. Furthermore, it draws attention to the need for appropriate human and material resources to ensure these needs can be adequately met in school settings.

There has been, to date, a large body of evidence documenting the significant link between academic success and social-emotional learning for all students (e.g., Caprara, Barbaranelli, Pastorelli, Bandura, and Zimbardo 2000; Durlak, Weissberg, Dymnicki, Taylor, 
and Schellinger 2011; Elias 2003; Payton et al. 2008). Despite recognition of this, socialemotional learning and support to develop social competence continues to be an often controversial and under-utilised source of learning in education contexts for all students (Humphrey, Curran, Morris, Farrell, and Woods 2007) and specifically students on the spectrum (Bauminger 2002; Bellini 2008; Gates, Kang, and Lerner 2017). Social-emotional learning in schools can be effective in supporting the development of social competence for this student group (Sansosti 2008) and needs to be more of a focus within learning environments. Additionally, professional development on current approaches for supporting social emotional needs such as the use of virtual reality, technology applications and robotics to support social understanding need to be made available and these strategies, where applicable, trialled and embedded in practice (Sze Ngar, \& Shing, 2018; Yun, Choi, Park, Bong, \& Yoo, 2017)

Another key theme highlighted by participants was the need for a transparent process for building school capacity to translate research and knowledge into practice by all stakeholders (including all staff members, therapists, parents and, all students). Suggested capacity building actions included improving awareness of a student's individual strengths and interests, and a focus on effectively supporting the unique needs of students on the spectrum. While findings suggested educators and specialists had stronger priorities in some areas, this is perhaps because of the bigger picture they can take across a class, school, district, or region based on the needs of a range of different students on the spectrum. Regardless, stakeholders who participated in the current research highlighted lack of funding, time, and support as barriers to effectively meeting the unique needs of students on the spectrum and emphasise the need for school systems to be providing adequate resourcing (human and material) to help address these barriers. 
These findings corroborate previous research that supporting the needs of students on the spectrum entails a whole-of-school approach for staff to develop knowledge, create a supportive environment, and utilise practices that support the unique learning styles of students on the spectrum (Humphrey 2008; Osborne and Reed 2011). Moreover, research has demonstrated that creating these types of supports across the school benefits students on the spectrum and creates a more inclusive setting that supports the needs of many students ([Author 6] and [Colleague] 2014; [Author 6] and [Colleague] 2015).

A multi-tiered approach to support for students on the spectrum offers promise as an integrated approach encompassing rights-based and needs-based perspectives of inclusive education (Gargiulo and Metcalf 2013; Magyar and Pandolfi 2012). This approach allows for the provision of specific support to students on the spectrum while also creating a support structure that benefits all students at the school. For example, within a tiered approach, support and intervention for social-emotional learning can focus on a school-wide, small group and individually focused responses to the "needs" of the students involved (Sansosti, 2008). While the approach allows educators an opportunity to go beyond catering for traditional academic and learning needs and is therefore highly suited to the diversity of students' needs in today's classrooms, which includes students on the spectrum (Gargiulo and Metcalf 2013; Magyar and Pandolfi 2012; Sansosti 2008). This requires transparent school policies and staff training within school communities. Professional development needs to be available through a flexible range of different modes including: face-to-face delivery, observation of others' practice (in-situ and on line); professional support methods (e.g., coaching); and through online delivery This will ensure that educators' build the knowledge and awareness of students' needs and strategies to effectively implement a tiered approach to support these needs using the most up to date strategies and contextualise them to the individual needs of the children in their care Fostering collaborative partnerships and 
gathering a "collective stakeholder voice" can be incorporated to ensure that students" ongoing needs are recognised and addressed. The collective voice of parents, educators and specialists stakeholders reflects the unique needs of students on the spectrum. This collective voice is important to ensure these needs are identified and adequate and appropriate support is implemented. This will ensure students on the spectrum can maximise their educational success and academic outcomes and highlights the power of collaboration with all stakeholders when working with students on the spectrum.

\section{Limitations}

While the findings provide important information to the field, limitations are evident including the cross sectional and self-report/self-selected nature of the survey,. Firstly, it was not possible to determine the total participant pool, therefore, a response rate could not be determined. However, there were some differences between completers and non-completers within the parents group, and between group differences between stakeholders in terms of experience, age, education level, and education setting (see online supplementary section S.1). An attempt was made to explore within group differences by conducting within-group analyses (see online supplementary sections S.4-S.6), however sample sizes were very small for some subgroups of educators and specialists, which may limit the generalisability of results. Other limitations include not considering the student perceptions for the purpose of this paper, as well as a lack of focus on post school transition and vocational preparation as a student need in school. Additionally the lack of equity in number in different stakeholder groups as well as between different state and geographical locations nationwide limits the generalisability of findings.

Recommendations for Future Research 
Findings of this research and the limitations encountered are the catalyst for a range of recommendation for future research including:

- An increase in research that includes multiple stakeholders views to ensure a collective voice from the autism community about the unique needs of students on the autism spectrum, supports required, professional development needs and barriers to translating research into practice

- A meta-analyses to help identify what professional development is best suited for meeting the needs of particular students and comparing different modes of delivery to meet the needs of educators

- A focus on including the student voice

- Investigations which look in detail at post school transition and vocation education as a focus of educational need

- Studies which strengthen findings of new approaches to social emotional learning in schools such as robotics and virtual reality

- Strengthening education evaluation studies using multiple methods of assessment; and

- Using long term follow-up studies to learn about how educational approaches maintain their impact when the child develops.

- Studies which investigate in more depth how the professional development needs of different geographical locations may vary for example, nationally, in comparison to metropolitan, regional and remote.

\section{Conclusions}

Disappointingly, despite the plethora of research conducted in the field of autism over the last 20 years, all stakeholders involved, and especially parents, indicated the needs of this groups 
of students continue not to be adequately met and successfully addressed in school systems. There was generally strong agreement on key findings by all stakeholder groups. It is important we continue to pursue and nurture a collective, collaborative view of the needs of this student group in educational settings to ensure we maximise success. Essential to success is to build awareness of the unique needs of students on the spectrum. Furthermore, to ensure success we need to provide tiers of support based on the diversity of needs experienced in today's classroom which also allow for additional external support and collaboration from specialist teachers, support staff, allied health professionals and external agencies in a preventative yet responsive approach to support not only all students in the classroom but also the educators and families.

\section{References}

American Psychiatric Association. (2013). Diagnostic and statistical manual of mental disorders (5th edn). Arlington, VA: American Psychiatric Association.

All Party Parliamentary Group on Autism (APPGA). 2017. Autism and education in England 2017.

https://webcache.googleusercontent.com/search?q=cache:SeZ1uJm3Mz8J:https://ww w.autism.org.uk/ /media/nas/documents/get-involved/held-back/appga-autism-andeducation-report.ashx $\% 3$ Fla\%3Den$\mathrm{gb}+\& \mathrm{~cd}=1 \& \mathrm{hl}=\mathrm{en} \& \mathrm{ct}=\mathrm{clnk} \& \mathrm{gl}=\mathrm{au} \& \mathrm{client}=$ firefox $-\mathrm{b}-\mathrm{d}$

Ashburner, J., Ziviani, J., \& Rodger, S. (2010). Surviving in the mainstream: Capacity of children with autism spectrum disorders to perform academically and regulate their emotions and behavior at school. Research in Autism Spectrum Disorders, 4(1), 18 27. doi: 10.1016/j.rasd.2009.07.002

Australian Advisory Board on Autism Spectrum Disorders. (2012). Education and Autism Spectrum Disorders in Australia: The provision of appropriate educational services for school-age students with Autism Spectrum Disorders in Australia. Position paper (2010) updated 2012. Frenchs Forest: Australian Advisory Board on Autism Spectrum Disorders. Retrieved from 
http://www.autismadvisoryboard.org.au/uploads/file/pdfs/Education $\% 20$ Position $\% 20$ Paper\%20Final\%202010\%20Final.pdf

[Author 1] et al. (2015). [Details hidden for blind review].

[Author 6], \& [Colleague]. (2014). [Details hidden for blind review].

[Author 6], \& [Colleague]. (2015). [Details hidden for blind review].

Baio, J., Wiggins, L., Christensen, D. L., Maenner, M. J., Daniels, J., Warren, Z., ...

Dowling, N. F. (2018). Prevalence of autism spectrum disorder among children aged 8 years - Autism and Developmental Disabilities Monitoring Network, 11 Sites, United States, 2014. MMWR Surveillance Summaries, 67(6), 1-23. doi: 10.15585/mmwr.ss6706a1

Baldry-Currens, J. A., \& Blithell, C. P. (2000). Clinical education: Listening to different perspectives. Physiotherapy, 86(12), 645-653.

Bauminger, N. (2002). The facilitation of social-emotional understanding and social interaction in high-functioning children with autism: Intervention outcomes. Journal of Autism and Developmental Disorders, 32(4), 283-298.

Bellini, S. (2008). Building social relationships: A systematic approach to teaching social interaction skills to children and adolescents with autism spectrum disorders and other social difficulties. Shawnee Mission, KS: Autism Asperger Publishing Company.

Cameron, R. (2009). A sequential mixed model research design: Design, analytical and display issues. International Journal of Multiple Research Approaches, 3(2), 140152.

Caprara, G. V., Barbaranelli, C., Pastorelli, C., Bandura, A., \& Zimbardo, P. G. (2000). Prosocial foundations of children's academic achievement. Psychological Science, 11, 302-306.

Centre for Studies in Inclusive Education (CSIE). (2008). Including disabled children in mainstream schools. Retrieved from http://www.csie.org.uk/inclusion/disabledchildren.shtml

[Colleague], [Author 6], \& [Colleague]. (2015). [Details hidden for blind review].

Creswell, J. W. (2012). Educational research: Planning, conducting, and evaluating quantitative and qualitative research. Boston, MA: Pearson.

den Houting, J. (2019). Neurodiversity: An insider's perspective. Autism, 23(2), 271-273. https://doi.org/10.1177/1362361318820762 
Driscoll, D. L., Appiah-Yeboah, A., Salib, P., \& Rupert, D. J. (2007). Merging qualitative and quantitative data in mixed methods research: How to and why not. Ecological and Environmental Anthropology, 3(1), 19-28.

Durlak, J., Weissberg, R. P., Dymnicki, A. B., Taylor, R. D., \& Schellinger, K. B. (2011). The impact of enhancing students' social and emotional learning: A meta-analysis of school-based universal interventions. Child Development, 82(1), 405-432.

Edwards, C. C., \& Da Fonte, A. (2012). The 5-point plan: Fostering successful partnerships with families of students with disabilities. Teaching Exceptional Children, 44(3), 6-13.

Elias, M. J. (2003). Academic and social-emotional learning. Geneva: International Bureau of Education.

Estes, A., Rivera, V., Bryan, M., Cali, P., \& Dawson, G. (2011). Discrepancies between academic achievement and intellectual ability in higher-functioning school-aged children with autism spectrum disorder. Journal of Autism and Developmental Disorders, 41(8), 1044-1052. doi: 10.1007/s10803-010-1127-3

Farrell, P., \& Ainscow, M. (Eds). (2002). Making special education inclusive: From research to practice. Abingdon: David Fulton Publishers.

Ferraioli, S., \& Harris, S. (2011). Effective Educational Inclusion of Students on the Autism Spectrum. Journal of Contemporary Psychotherapy, 41(1), 19-28. https://doi.org/10.1007/s10879-010-9156-y

Gargiulo, R. M., \& Metcalf, D. (2013). Teaching in today's inclusive classrooms: A universal design for learning approach ( $2^{\text {nd }}$ edn $)$. Belmont, CA: Wadsworth, Cengage Learning.

Gates, J., Kang, E., \& Lerner, M. (2017). Efficacy of group social skills interventions for youth with autism spectrum disorder: A systematic review and meta-analysis. Clinical Psychology Review, 52, 164-181. doi: 10.1016/j.cpr.2017.01.006

Gavin, H. (2008). Understanding research methods and statistics in psychology. London: SAGE Publications Ltd.

Gillett-Swan, J. K. \& Coppock, V. (2016). Children's rights, educational research and the UNCRC: past, present and future. Symposium Books, United Kingdom.

Grimshaw, J. M., Eccles, M. P., Lavis, J. N., Hill, S. J., \& Squires, J. E. (2012). Knowledge translation of research findings. Implementation Science: IS, 7, 50. doi: 10.1186/17485908-7-50

Hebron, J., \& Humphrey, N. (2014). Mental health difficulties among young people on the autistic spectrum in mainstream secondary schools: A comparative study. Journal of 
Research in Special Educational Needs, 14, 22-32. doi: 10.1111/j.14713802.2012.01246.x.

Humphrey, N. (2008). Including pupils with autistic spectrum disorders in mainstream schools. Support for Learning, 23, 41-47.

Humphrey, N., Curran, A., Morris, E., Farrell, P., \& Woods, K. (2007). Emotional intelligence and education: A critical review. Educational Psychology, 27(2), 235254. doi: $10.1080 / 01443410601066735$

Humphrey, N., \& Symes, W. (2011). Peer interaction patterns among adolescents with autistic spectrum disorders (ASDs) in mainstream school settings. Autism, 15, 397419. doi: $10.1177 / 1362361310387804$.

Humphrey, N., \& Symes, W. (2013). Inclusive education for pupils with autistic spectrum disorders in secondary mainstream schools: Teacher attitudes, experience and knowledge. International Journal of Inclusive Education, 17(1), 32-46. doi: $10.1080 / 13603116.2011 .580462$

Ivankova, N. V., Cresswell, J. W., \& Stick, S. L. (2006). Using mixed-methods sequential explanatory design: From theory to practice. Field Methods, 18(1), 3-20. doi: $10.1177 / 1525822 \times 05282260$

Jones, C. R., Happe, F., Golden, H., Marsden, A. J., Tregay, J., Simonoff, E., ... Charman, T. (2009). Reading and arithmetic in adolescents with autism spectrum disorders: Peaks and dips in attainment. Neuropsychology, 23(6), 718-728. doi: 10.1037/a0016360

Kurth, J., \& Mastergeorge, A. (2010). Academics and cognitive profiles of students with autism: Implications for classroom practice and placement. International Journal of Special Education, 25, 8-14.

Lindsay, G. (2007). Educational psychology and the effectiveness of inclusive education/mainstreaming. British Journal of Educational Psychology, 77, 1-24.

Lindsay, G., Ricketts, J., Peacey, L., Dockrell, J., \& Charman, T. (2016). Meeting the Educational and Social Needs of Children with Language Impairment or Autism Spectrum Disorder: The Parents' Perspectives. International Journal of Language \& Communication Disorders, 51(5), 495-507. https://doi.org/10.1111/1460-6984.12226

Low, C. (2007). A defence of moderate inclusion and the end of ideology. In R. Cigman (Ed.), Included or excluded? The challenge of the mainstream for some SEN children (pp. 15-23). London: Routledge. 
Magyar, C. I., \& Pandolfi, V. (2012). Considerations for establishing a multi-tiered problemsolving model for students with autism spectrum disorders and comorbid emotional behavioral disorders. Psychology in the Schools, 49(10), 975-987.

Menold, J., Jablokow, K.W., Purzer, S., Ferguson, D.M., \& Ohland, M.W. (2015). Using an Instrument Blueprint to Support the Rigorous Development of New

Surveys and Assessments in Engineering Education. $122^{\text {nd }}$ American Society for Engineering Education (ASEE). Seattle June 14-17, 2015.

Messick, Samuel. Validity of psychological assessment: validation of inferences from persons' responses and performances as scientific inquiry into score meaning. American Psychologist 50.9 (1995): 741.

Okajima, J., Kato, N., Yoshitomi, Y., Kanaya, R., \& Sakuta, R. (2017). The characteristics of social skills, school maladjustment and stress responses in junior high school students with autism spectrum disorder. No To Hattatsu, 49(2), 120-125. https://doi.org/10.11251/ojjscn.49.120

Onwuegbuzie, A. J., \& Teddlie, C. (2003). A framework for analyzing data in mixed methods research. In A. Tashakkori \& C. Teddlie (Eds.), Handbook of mixed methods in social and behavioral research (pp. 351-383). Thousand Oaks, CA: Sage.

Osborne, L. A., \& Reed, P. (2011). School factors associated with mainstream progress in secondary education for included pupils with Autism Spectrum Disorders. Research in Autism Spectrum Disorders, 5, 1253-1263. doi: 10.1016/j.rasd.2011.01.016.

Patton, M. Q. (2002). Qualitative research and evaluation methods ( $3^{\text {rd }}$ ed.). Thousand Oaks, CA: Sage.

Payton, J., Weissberg, R. P., Durlak, J. A., Dymnicki, A. B., Taylor, R. D., Schellinger, K. B., \& Pachan, M. (2008). The positive impact of social and emotional learning for kindergarten to eighth-grade students: Technical report - Findings from three scientific reviews. Chicago, IL: Collaborative for Academic, Social, and Emotional Learning (CASEL).

Pellicano, L., Bölte, S., and A. Stahmer. (2018). “The Current Illusion of Educational Inclusion." Autism, 22 (4): 386-387.

Pellicano, L., Dinsmore, A., \& Charman, T. (2014). What should autism research focus upon? Community views and priorities from the United Kingdom. Autism, 18(7), 756-770. doi: 10.1177/1362361314529627 
Powers, B. A., \& Knapp, T. A. (Eds). (2010). Dictionary of nursing theory and research (4 ${ }^{\text {th }}$ edn). New York, NY: Springer Publishing.

Ravet, J. (2011). Inclusive/exclusive? Contradictory perspectives on autism and inclusion: The case for an integrative position. International Journal of Inclusive Education, 15(6), 667-682.

Roberts, J., \& Simpson, K. (2016). A review of research into stakeholder perspectives on inclusion of students with autism in mainstream schools. Journal of Inclusive Education, 20(10), 1084-1096. doi: 10.1080/13603116.2016.1145267

Sansosti, F. (2010). Teaching social skills to children with autism spectrum disorders using tiers of support: A guide for school-based professionals. Psychology in the Schools, 47(3), 257-281.

Sansosti, J. M. (2008). The meaning and means of inclusion for students with autism spectrum disorders: A qualitative study of educators' and parents' attitudes, beliefs, and decision-making strategies (PhD thesis). University of South Florida, USA.

Sansosti, J., \& Sansosti, F. (2012). Inclusion for students with high-functioning autism spectrum disorders: Definitions and decision making. Psychology in the Schools, 49, 917-931. doi: 10.1002/pits.21652.

Siegel, B. (2018). The politics of autism. New York, NY, United States of America: Oxford University Press.

Soriano, F. (2013). Conducting needs assessments: a multidisciplinary approach (2nd ed.). Thousand Oaks, Calif: SAGE.

Soto-Chodiman, R. E., Pooley, J., Cohen, L., \& Taylor, M. F. (2012). Students with ASD in mainstream primary education settings: Teachers' experiences in Western Australian classrooms. Australasian Journal of Special Education, 36(2), 97-111.

Stokes, M., Thomson, M., Macmillan, C., Pecora, L., Dymond, S., \& Donaldson, E. (2017). Principals' and Teachers' Reports of Successful Teaching Strategies with Children with High-Functioning Autism Spectrum Disorder. Canadian Journal of School Psychology, 32(3-4), 192-4), p.192-208. https://doi.org/10.1177/0829573516672969

Sze Ngar, V. Y., \& Shing, H. H. (2018). Using virtual reality to train emotional and social skills in children with autism spectrum disorder. London Journal of Primary Care, 10(4) doi:http://dx.doi.org.ezp01.library.qut.edu.au/10.1080/17571472.2018.1483000

United Nations Educational Scientific and Cultural Organisation. (1994). Salamanca Statement and Framework for Action on Special Needs. Salamanca: UNESCO. 
Waddington, E. M., \& Reed, P. (2017). Comparison of the effects of mainstream and special school placements on National Curriculum outcomes in children with autism spectrum disorder: An archive-based analysis. Journal of Research in Special Educational Needs, 17(2), 132-142. doi: 10.1111/1471-3802.12368

Yun, S. , Choi, J. , Park, S. , Bong, G. and Yoo, H. (2017), Social skills training for children with autism spectrum disorder using a robotic behavioral intervention system. Autism Research, 10: 1306-1323. doi:10.1002/aur.1778 


\section{Figure captions:}

Figure 1. Perception of educational needs and barriers to support

Figure 2. Participant perceptions of the needs of students on the autism spectrum 